\title{
Implicit memory in multiple sclerosis
}

\author{
G. Latchford'1 , S. Morley' ${ }^{1}$, K. Peace ${ }^{2}$ and J. Boyd ${ }^{1}$ \\ ${ }^{1}$ Academic Unit of Psychiatry, University of Leeds, School of Medicine, 15 Hyde \\ Terrace, Leeds LS2 9JT, and 'Department of Clinical Psychology, St James's University \\ Hospital, Beckett Street, Leeds LS9 7TF, UK
} Correspondence to: G. Latchford, York Clinical Psychology Services, Clifton Hospital,
Shipton Road, York YO3 6RD, UK

\begin{abstract}
A number of neuropsychological studies have revealed that memory problems are relatively common in patients with multiple sclerosis (MS). It may be useful to compare MS with conditions such as Huntington's disease (HD), which have been referred to as subcortical dementia. A characteristic of these conditions may be an impairment in implicit (unconscious) memory, but not in explicit (conscious) memory. The present study examined the functioning of explicit and implicit memory in MS. Results showed that implicit memory was not significantly impaired in the MS subjects, and that they were impaired on recall but not recognition. A correlation was found between implicit memory performance and disability status in MS patients. Findings also suggest the possibility of long-term priming of implicit memory in the control subjects. The implications of these results are discussed.
\end{abstract}

Keywords: Implicit memory - Memory - Multiple sclerosis - Subcortical dementia

\section{INTRODUCTION}

Multiple sclerosis (MS) is a common demyelinating disease of the central nervous system characterized by scattered lesions (plaques) in the white matter of the brain and spinal cord. Disturbance of memory has been one of the most consistent findings in neuropsychological investigations of MS and it is now well established that up to $40 \%$ of MS patients may report memory loss "as a clinically noticeable problem" (Rao et al., 1984). The overwhelming consensus of findings from studies which have compared MS patients with controls on memory tasks is that free recall is impaired, but recognition and short-term memory are largely intact. Observations obtained from other neurological conditions are useful in evaluating possible explanations for these findings. In particular, the pattern of memory impairment in Huntington's disease (HD) appears to be similar to that found in MS. Poor verbal fluency in HD suggests a retrieval problem (Butters et al., 1986), and similar poor verbal fluency in MS has led many to suggest a similar deficit (e.g. Rao et al., 1989; Minden et al., 1990).

The pattern of intellectual impairments seen in conditions such as HD and Parkinson's disease (PD) have been described in terms of subcortical dementia syndrome (McHugh and Folstein, 1975). This is characterized by features such as slowness of mental processing, failure in memory retrieval with intact encoding, and absence of language disturbance, and by mainly subcortical pathology

C) 1993 Rapid Communications of Oxford Ltd
(Cummings and Benson, 1984; Cummings, 1986). It has been contrasted with cortical dementias such as Alzheimer's disease (AD).

Similarities have been observed in the overall pattern of intellectual deficits in matched groups of HD and MS patients (Caine $e$ t al., 1986), and distinct neuropsychological profiles have been identified between groups of MS and $\mathrm{AD}$ patients, when controlling for overall level of dementia (Filley et al., 1989). These authors have argued for the identification of MS as a subcortical dementia, although this is difficult to reconcile with the fact that pathology in MS is not exclusively subcortical. Such a comparison may suggest useful directions for research, however. In particular, implicit memory has been studied in subcortical dementia but has not yet been studied in MS.

Studies of memory in MS have used recall and recognition methods, which require conscious and wilful encoding and recollection, and can be considered tests of explicit memory. In contrast, experimental tasks have been devised in which information is expressed without conscious encoding or recollection. This has been described as implicit memory (e.g. Graf and Schacter, 1985). One such task is repetition priming, in which subjects are exposed to a word list, then given a word completion task in which they are shown a word stem (e.g. TAB _ for table) and instructed to complete it with the first word that comes to mind. The increased probability that stems will 
be completed as words to which the subject was exposed on the prior study list, represents the action of implicit memory. Many studies have demonstrated an apparent dissociation of implicit and explicit memory (e.g. Shimamura, 1986).

It has been argued that an impairment in implicit memory may be a feature of subcortical dementia. Using an explicit memory task (recognition) and an implicit skill learning task (mirror reading), Martone et al. (1984) found a double dissociation between patients with HD and Korsakoff's syndrome, the latter performing well on the implicit and poorly on the explicit task, while the HD patients produced the reverse pattern. They concluded that HD patients appear to have a preserved explicit memory but an impaired implicit memory. In contrast, a study by Nebes et al. (1984) has shown that patients with AD appear to have a normal capacity for implicit memory, as measured using a semantic priming task, and an impaired explicit memory, as measured on tests of episodic memory. Although a study of patients with PD, using different tests of implicit memory such as identification of stimulus modality, did not find this pattern (Weingartner et al., 1984), the suggestion that the neurological basis of implicit memory can be localized to subcortical structures and that deficits are a characteristic of the subcortical dementia syndrome appears to be worthy of further investigation.

The present study examined implicit and explicit memory functioning in MS. If, as Filley et al. (1989) argue, MS can be considered a subcortical dementia, one would predict that an impaired implicit memory and a functioning explicit memory would be a characteristic feature of this condition. If so, this would provide support for the application of the subcortical dementia concept to MS.

\section{METHODS}

\section{Design}

A repeated-measures, between-subject design was used. An MS and control group were compared on recall, recognition and stem completion tasks. The measures were repeated with a different word list (A or B) after 1 month. Subjects were randomly allocated to have word list A or B presented first.

The design enabled a baseline score for stem completion to be obtained for each subject. The two word lists were presented at different times, but both times were followed by a stem completion task using the word stems of both word lists. Thus, when a subject was presented with word list A on the first occasion, the word stems for words from list A were primed and the word stems for list B were not. On the next occasion, list B was presented and this list was primed in the stem completion task. Performance on each list in primed and non-primed conditions was compared, with each subject acting as their own baseline.

\section{Subjects}

Twelve subjects diagnosed as having a relapsing/remitting form of MS by a consultant physician were recruited through the local MS society. Their mean age was 50 (S.D. $=13.4)$. The average time since onset of MS symptoms, as reported by the subjects, was 13.8 years. All MS subjects were assessed by G.L. using the Kurtzke Expanded Disability Scale (Kurtzke, 1983). Control subjects were matched for sex, age (within a maximum of 5 years) and social class. Mean age of control subjects was 49.9 years $($ S.D. $=13.8)$.

\section{Materials}

The explicit memory tests consisted of a free recall and a recognition task. The implicit memory test was a stem completion task based upon the same word list.

Thirty-two test words were divided into two sets, A and B. They were all of low frequency. They were printed in black ink $12 \mathrm{~mm}$ high, on white cards, as were the word stems. Thirty-six word stems were used. Thirty-two of these consisted of the first three letters of the words in word lists A and B (thus MAR___ is the word stem for MARBLE). In addition, four word stems were not related to the words on the word lists. These were used as practice items presented first in all stem completion tests.

Two distractor tasks were used between presentation of the word list and testing; the digit span subtest of the WAIS-R, and the shortened version of the Token Test (DeRenzi and Faglioni, 1978).

\section{Procedure}

The subject was instructed to memorize a list of words for a memory test and the word list was presented, one word every $5 \mathrm{~s}$. This was followed by the first distractor task, then a second presentation of the same test words, then the second distractor task. The subjects were then given the stem completion task and instructed to complete the stems with the first word that came to mind. No mention was made by the experimenter of any connection with the previous word list or memory test. The subject was next asked to recall any words from the word list presented in that session. Lastly, the subject was given a forced-choice recognition task, where $50 \%$ of the words were stimulus items and 50\% new items. Words for the recognition task were taken from both word lists in random order. This procedure was repeated in the next session with the second word list.

\section{RESULTS}

All tasks were scored using strict criteria allowing no variations on the target. Recognition was scored using the cor- 
rection for guessing method (Baddeley, 1990), whereby the true detection rate is given by the true positives minus the false positives. Production of target words on the stem completion task after exposure was ascribed to chance and not counted if it also appeared in the baseline condition without exposure. This method of eliminating chance completions was applied in both sessions.

The data from the two presentations of the memory tests for the MS and control groups were analysed using a twoway ANOVA. Mean scores for both groups on the free recall, recognition and stem completion tests are given in Table I, and are shown graphically in Fig. 1.

The MS group performed significantly poorer than the control group on recall $(\mathrm{F}=6.26, \mathrm{df}=1,22, p=0.02)$. The difference in recognition scores was not significant between the groups, though there was a ceiling effect, with five control subjects scoring maximally in at least one of the presentations. There was no significant difference between the groups on the stem completion task. No significant differences were found between the sessions on recall or recognition. A significant difference was found between the sessions on the stem completion task $(F=6.74$, $\mathrm{df}=1,22, p=0.016$ ), with fewer completions in the first session.

Pearson's product-moment correlations were computed to identify factors which it was hypothesized might have affected the performance of the MS group. Score on the Kurtzke disability status correlated highly with summed performance on stem completion $(r=-0.822$, $\mathrm{df}=10$, $p=0.001$ ), but not with recall or recognition. Disability status also correlated with age $(r=0.604, \mathrm{df}=10$, $p=0.019$ ), and there is therefore the possibility that age may be underlying this effect. In order to determine the correlation between disability status and stem completion performance whilst keeping the age variable constant, a Kendall Partial Rank Correlation Coefficient was com-

TABLE I. Scores on memory tests for MS and control subjects

\begin{tabular}{|c|c|c|c|c|}
\hline \multirow[b]{3}{*}{ Test } & \multicolumn{4}{|c|}{ Group } \\
\hline & \multicolumn{2}{|c|}{ MS } & \multicolumn{2}{|c|}{ Controls } \\
\hline & Mean & S.D. & Mean & S.D. \\
\hline \multicolumn{5}{|l|}{ Recall } \\
\hline Session 1 & 4.8 & 1.7 & 7.8 & 4.5 \\
\hline Session 2 & 4.9 & 2.6 & 8.3 & 3.7 \\
\hline Both sessions & 4.85 & 2.15 & 8.05 & 4.1 \\
\hline \multicolumn{5}{|l|}{ Recognition } \\
\hline Session 1 & 11.5 & 2.0 & 12.6 & 3.3 \\
\hline Session 2 & 10.1 & 2.9 & 12.3 & 2.3 \\
\hline Both sessions & 10.8 & 2.45 & 12.45 & 2.8 \\
\hline \multicolumn{5}{|l|}{ Stem completion } \\
\hline Session 1 & 2.6 & 1.2 & 3.6 & 2.7 \\
\hline Session 2 & 4.0 & 3.0 & 4.8 & 2.8 \\
\hline Both sessions & 3.3 & 2.1 & 4.2 & 2.75 \\
\hline
\end{tabular}

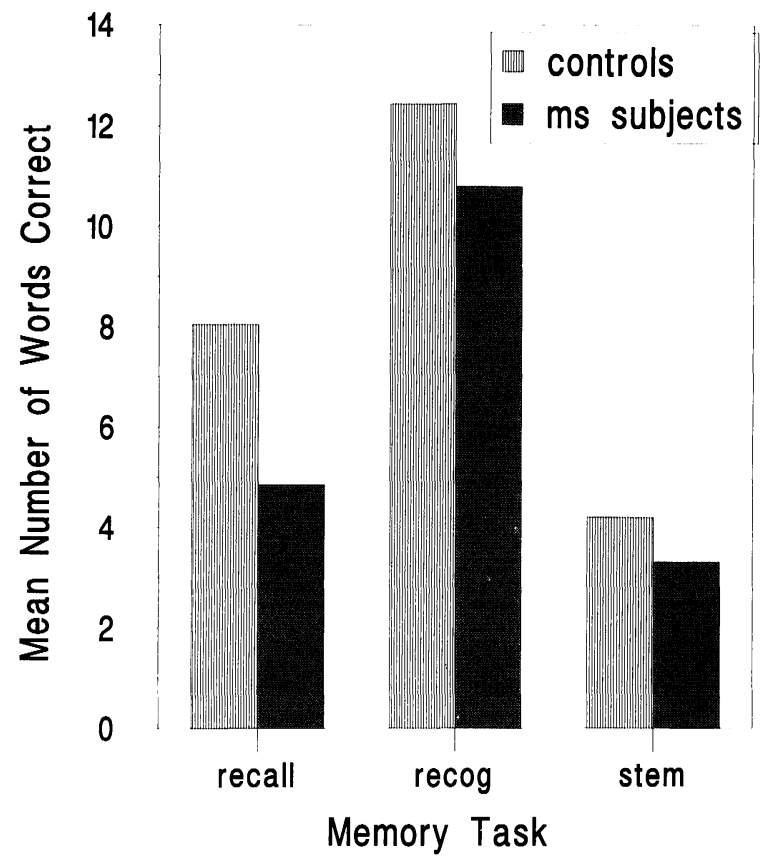

FIG. 1. Mean performance of subjects on memory tasks.

puted. This produced a coefficient $(r=-0.736, \mathrm{df}=10$, $p=0.001$ ) only slightly lower than the original correlation. Disability status, therefore, did indeed correlate with stem completion. Duration of MS did not correlate with performance on the memory tasks.

\section{DISCUSSION}

The finding of a significant difference on free recall but not on recognition confirms earlier observations (e.g. Rao, 1986). The test of implicit memory did not reveal a significant difference between the groups, though a correlation was found between implicit memory and disability status in the MS subjects.

There was a significant difference between the sessions on the stem completion task. As a similar difference was not found in either the recall or recognition task it is unlikely to have been due to a practice effect. An alternative explanation is that there was a source of error in the testing and scoring procedure. Although the same method of eliminating chance completions was applied to responses from both sessions, there was an important difference between them: for the baseline stem completions in the second session exposure to the word list had occurred before, during the previous session. It was assumed that a previous exposure would have no effect on performance after an interval of 1 month. To investigate this possibility a comparison was made of the number of correct stem completions ascribed to chance in the two sessions. In the MS subjects, five completions were not allowed in session 
1 (where there had been an exposure to the word list 1 month before the baseline was taken) and four in session 2 (where there was no prior exposure). In the control subjects, one completion was not allowed in session 2, and 12 in session 1 . For control subjects, then, this suggests that there is a possibility that earlier exposure had a confounding effect and that a form of long-term priming occurred leading to an underestimate of their performance. This contradicts previous research which has found priming effects to be very short lasting (e.g. Squire et al., 1985). An alternative possibility is that subjects may have consciously tried to remember the previous word list before the second session, in the false belief that they would be tested on it. This may have "re-primed" the words in implicit memory.

The present study did not find a deficit in implicit memory functioning in MS comparable with that observed in patients with HD by Martone et al. (1984). The two studies used different implicit memory tasks (stem completion and mirror reading), however, and conclusions about the relative functioning of implicit memory in MS and HD can only be made if the tasks assess the same memory system. Coltheart (1989) has argued that implicit memory may consist of more than one system, and this supposes that a dissociation is possible within implicit memory, and that it is possible to be selectively impaired on only one subsystem. There is some evidence to support this view. Bondi and Kaszniak (1991) compared patients with PD and $\mathrm{AD}$ on explicit memory tests and a variety of implicit memory tests: picture completion, word stem completion, pursuit-rotor tracking, and mirror reading. They found that the AD patients were impaired on all explicit tests and on only one implicit test-stem completion. The PD patients were not impaired on explicit tests but were selectively impaired on some but not all of the implicit tests: primarily the skill learning component of the picture completion task. If a distinction between subsystems in implicit memory is accepted, then many examples of apparently contradictory findings in previous research may be reconciled (e.g. Martone et al., 1984; Weingartner et al., 1984).

The present study did not find evidence of impaired implicit verbal memory in MS. It did find a correlation between stem completion performance and disability status which suggests that there is a deterioration in performance linked with increased disability. Is there an explanation for this? Heindel et al. (1989) have shown that both AD patients and demented PD patients-but not nondemented PD patients-are impaired on stem completion tasks. This suggests that impairment in word priming is related to damage to the cerebral cortex. It may be that the correlation between disability status and stem completion found in the present study represents the degree of demyelination damage to the cortex, revealed through impaired performance. Such damage may only be a feature of the more severe stages of the illness, where the amount of damage and number of different sites of demyelination are greater. Although many studies have not found a relationship between deficits in cognitive performance and disability status (e.g. Beatty et al., 1990), such an association has been found when community rather than in-patient samples of MS patients are used (McIntosh-Michaelis et al., 1991).

\section{REFERENCES}

Baddeley A (1990) Human Memory: Theory and Practice. Lawrence Erlbaum, Hove.

Beatty W, Goodkin D, Hertsgaard D and Monson N (1990) Clini$\mathrm{cal}$ and demographic predictors of cognitive performance in multiple sclerosis. Archives of Neurology, 47, 305-308.

Bondi M and Kaszniak A (1991) Implicit and explicit memory in Alzheimer's disease and Parkinson's disease. Journal of Clinical and Experimental Neuropsychology, 13, 339-358.

Butters N, Martone M, White B, Granholm E and Wolfe J (1986) Clinical validators: Comparisons of demented and amnesic patients. In: Clinical Memory Assessment of Older Adults (ed. L Poon). American Psychological Association, Washington, DC.

Caine E, Bamford K, Schiffer R, Shoulson I and Levy S (1986) A controlled neuropsychological comparison of Huntington's disease and multiple sclerosis. Archives of Neurology, 43, 249-254.

Coltheart M (1989) Implicit memory and the functional architecture of cognition. In: Implicit Memory: Theoretical Issues (eds S Lewandowsky, J Dunn and K Kirsner). Lawrence Erlbaum Associates, Hillsdale, NJ.

Cummings J (1986) Subcortical dementia: neuropsychology, neuropsychiatry, and pathophysiology. British Journal of Psychiatry, 149, 682-697.

Cummings J and Benson D (1984) Subcortical dementia: Review of an emerging concept. Archives of Neurology, 41, 874-879.

DeRenzi E and Faglioni P (1978) Normative data and screening power of a shortened version of the Token Test. Cortex, 14, 41 .

Filley C, Heaton R, Nelson L, Burks J and Franklin G (1989). A comparison of dementia in Alzheimer's disease and multiple sclerosis. Archives of Neurology, 46, 157-161.

Graf P and Schacter D (1985) Implicit and explicit memory for new associations in normal and amnesic subjects. Journal of Experimental Psychology: Learning, Memory, and Cognition, 11, 501-518.

Heindel W, Salmon D, Shults C, Walicke P and Butters N (1989) Neuropsychological evidence for multiple implicit memory systems: a comparison of Alzheimer's, Huntington's and Parkinson's disease patients. Journal of Neuroscience, 9, 582-587.

Kurtzke JF (1983) Rating neurologic impairment in multiple sclerosis: an expanded disability status scale (EDSS). Neurology, 33, 1444-1452.

Martone M, Butters N, Payne M, Becker J and Sax D (1984) Dissociations between skill learning and verbal recognition in amnesia and dementia. Archives of Neurology, 41, 965-970.

McCollough C (1965) Colour adaptation of edge-detectors in the human visual system. Science, 149, 1115-1116.

McHugh P and Folstein M (1975) Psychiatric syndromes of Huntington's chorea: a clinical and phenomenological study. 
In: Psychiatric Aspects of Neurologic Disease (eds D Benson and D Blumer). Grune and Stratton, New York.

McIntosh-Michaelis SA, Roberts MH, Wilkinson SM, Diamond ID, McLellan DL, Martin JP and Spackman AJ (1991) The prevalence of cognitive impairment in a community survey of multiple sclerosis. British Journal of Clinical Psychology, 30, 333-348.

Minden S, Moes E, Orav J, Kaplan E and Reich P (1990) Memory impairment in multiple sclerosis. Journal of Clinical and Experimental Neuropsychology, 12, 566-586.

Nebes R, Martin D and Horn L (1984) Sparing of semantic memory in Alzheimer's disease. Journal of Abnormal Psychology, 93, 321-330.

Rao S (1986) Neuropsychology of multiple sclerosis: A critical review. Journal of Clinical and Experimental Neuropsychology, 8, 503-542.

Rao S, Hammeke T, McQuillen M, Khatri B and Lloyd D (1984)
Memory disturbance in chronic progressive multiple sclerosis. Archives of Neurology, 41, 625-631.

Rao S, Leo G and St Aubin-Faubert P (1989) On the nature of memory disturbance in multiple sclerosis. Journal of Clinical and Experimental Neuropsychology, 11, 699-712.

Shimamura A (1986) Priming effects in amnesia: evidence for a dissociable memory function. Quarterly Journal of Experimental Psychology, 38, 619-644.

Squire L, Shimamura A and Graf P (1985) Independence of recognition memory and priming effects. Journal of Experimental Psychology: Learning, Memory, and Cognition, 11, 37-44. Weingartner H, Burns S, Diebel R and LeWitt P (1984) Cognitive impairments in Parkinson's disease: distinguishing between effort-demanding and automatic cognitive processes. Psychiatry Research, 11, 223-235.

(Received 9 June 1993; accepted 21 June 1993) 


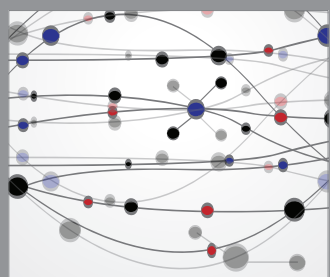

The Scientific World Journal
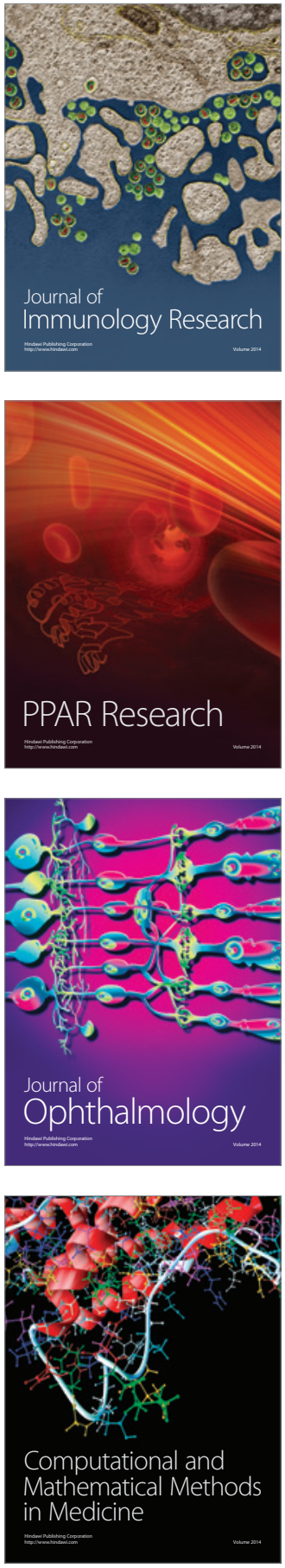

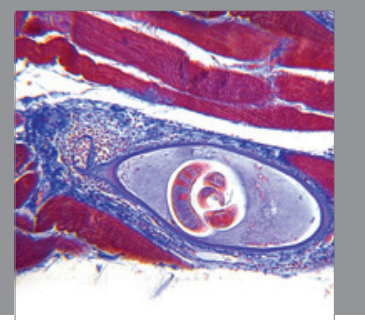

Gastroenterology

Research and Practice
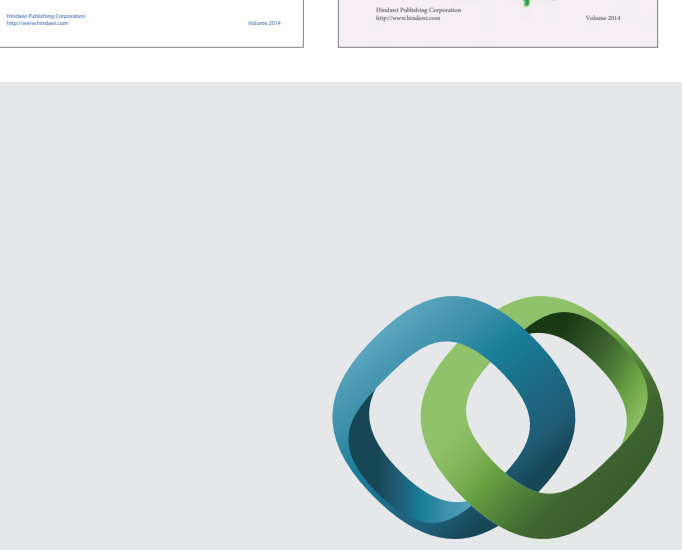

\section{Hindawi}

Submit your manuscripts at

http://www.hindawi.com
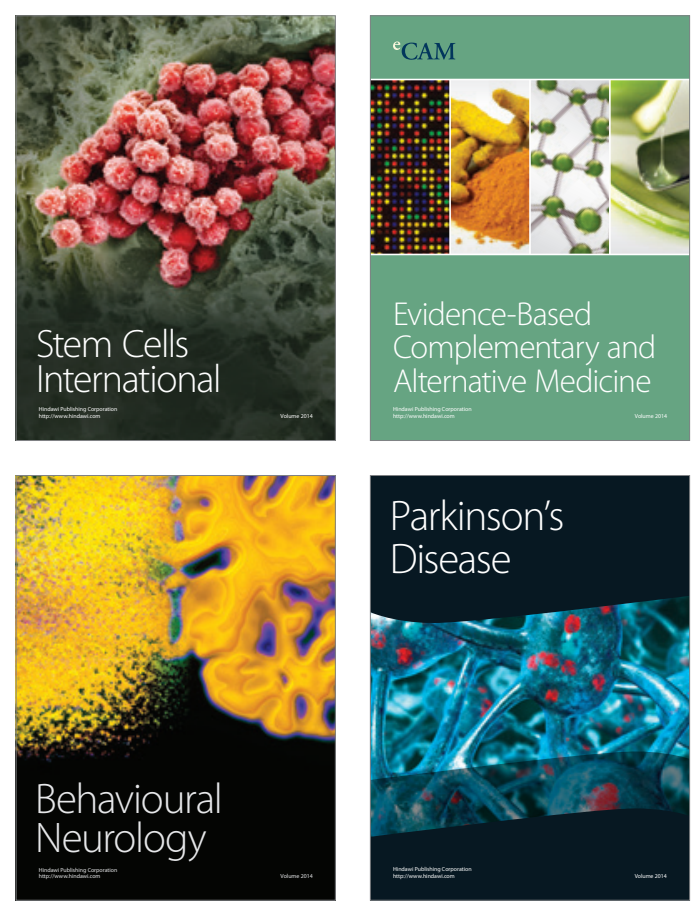

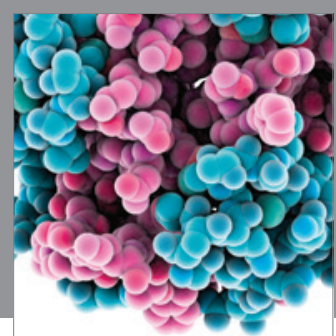

Journal of
Diabetes Research

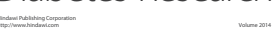

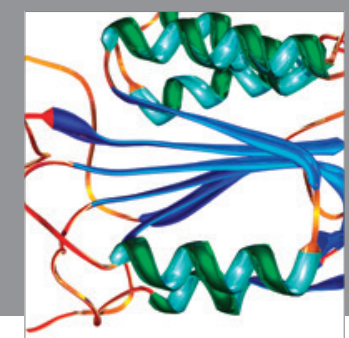

Disease Markers
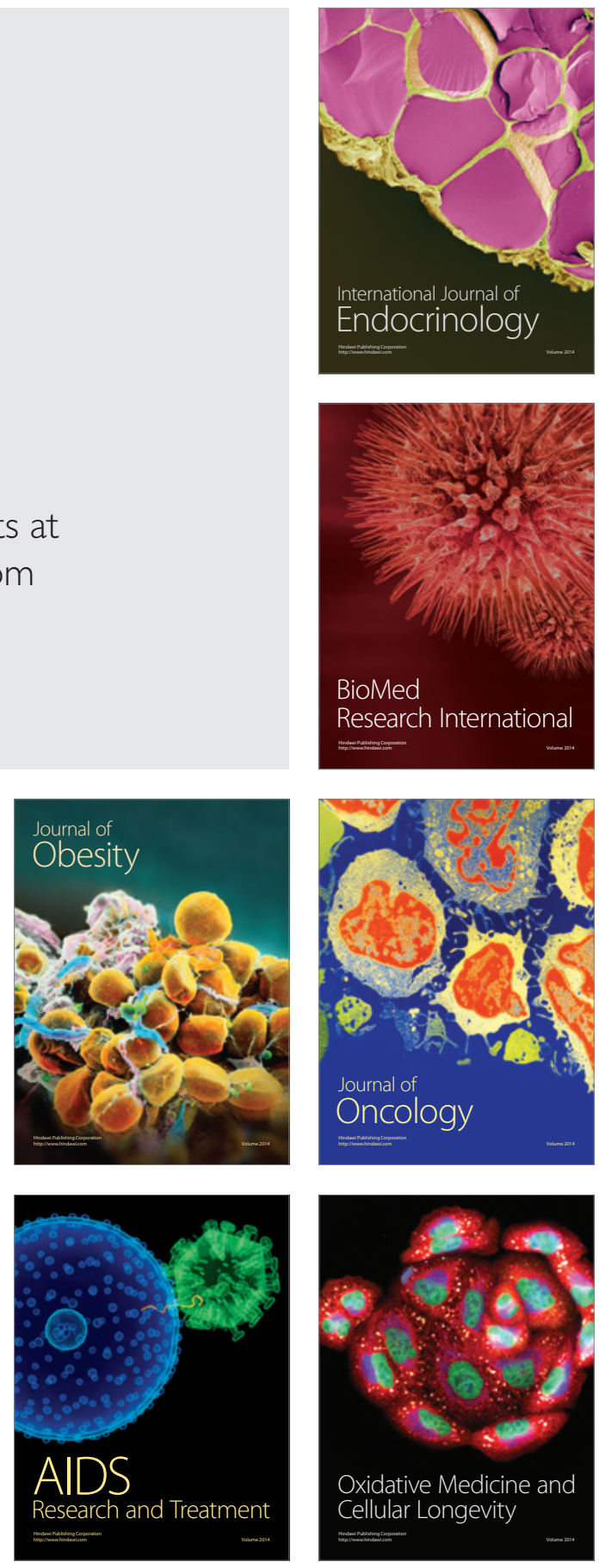